\title{
Chemical Bonding and Magnetic Properties of Gadolinium (Gd) Substituted
}

\section{Cobalt Ferrite}

\author{
Venkata Sreenivas Puli ${ }^{1, *}$, Shiva Adireddy ${ }^{2}$, and C.V. Ramana ${ }^{1}$ \\ ${ }^{1}$ Department of Mechanical Engineering, University of Texas, El Paso, Texas 79968, USA \\ ${ }^{2}$ Department of Physics and Engineering Physics, Tulane University, New Orleans, Louisiana, \\ 7118, USA
}

${ }^{*}$ Author to whom correspondence should be addressed; Email: vspuli@.utep.edu 


\begin{abstract}
Polycrystalline gadolinium (Gd) substituted cobalt ferrites $\left(\mathrm{CoFe}_{2-x} \mathrm{Gd}_{x} \mathrm{O}_{4} ; x=0-0.3\right.$, referred to CFGO) ceramics have been synthesized by solid state reaction method. Chemical bonding, crystal structure and magnetic properties of CFGO compounds have been evaluated as a function of Gd-content. X-ray diffraction and Raman spectroscopic analyses confirmed the formation of inverse spinel structure. However, a secondary ortho-ferrite phase $\left(\mathrm{GdFeO}_{3}\right)$ nucleates for higher values of Gd-content. A considerable increase in the saturation magnetization has been observed upon the initial substitution of $\mathrm{Gd}(x=0.1)$. The saturation magnetization drastically decreases at higher $\mathrm{Gd}$ content $(x \geq 0.3)$. No contribution from ortho-ferrite $\mathrm{GdFeO}_{3}$ phase is noted to the magnetic properties. The increase in the magnetic saturation magnetization is attributed to the higher magnetic moment of $\mathrm{Gd}^{3+}\left(4 \mathrm{f}^{7}\right)$ residing in octahedral sites is higher when compared to that of $\mathrm{Fe}^{3+}\left(3 \mathrm{~d}^{5}\right)$ and as well due to the migration of $\mathrm{Co}^{2+}\left(3 \mathrm{~d}^{7}\right)$ ions from the octahedral to the tetrahedral sites with a magnetic moment aligned anti-parallel to those of rare earth $\left(\mathrm{RE}^{3+}\right)$ ions in the spinel lattice. Increase in coercivity with increase in $\mathrm{Gd}^{3+}$ is content is attributed to magnetic anisotropy in the ceramics.
\end{abstract}

Keywords: Cobalt Ferrite; Gd-Substitution; Raman Spectroscopy; Magnetic properties; Neel temperature; 


\section{Introduction}

Ferrimagnetic materials, are an important class of magnetic ceramics, have drawn much attention for the past few decades due to their remarkable properties like high saturation magnetization, large permeability at high frequency, low eddy current, and high electrical resistivity to be utilized in solid state electronics and magneto-electronics [1-15].

Particularly, rare earth (RE) ion substituted spinel ferrites are reported to be promising candidates for applications in high-density storage (magnetic cores of read write heads for highspeed digital tape or disk recording), magnetic sensors, magnetic fluids, telecommunication equipments, magnetically guided drug or radioactive nuclide delivery, and remote detoxification, radio frequency coils, transformer cores, rod antennas, and are also good candidates for microwave applications [2-3].

In $\mathrm{AB}_{2} \mathrm{O}_{4}$ type centrosymmetric spinel ferrites, the metal ions are situated in two different sublattices designated tetrahedral (A-site) and octahedral (B-site) in a unit cell. Magnetic and electrical properties of these ferrites depend on the nature and distribution of their cations in the two tetrahedral and octahedral sub-lattices of a cubic structure [4,5]. These high Curie temperature magnetic insulators can also be used in spintronics [6] and spincaloritronics (spintransfer torque devices) [7] applications due to their natural non-zero magnetic moment along with spin dependent band gaps. Recently, $\mathrm{AB}_{2} \mathrm{O}_{4}$ spinel crystalline structured ceramics $\left(\mathrm{CoFe}_{2} \mathrm{O}_{4}, \mathrm{NiFe}_{2} \mathrm{O}_{4}, \mathrm{Ni}_{0.65} \mathrm{Zn}_{0.35} \mathrm{Fe}_{2} \mathrm{O}_{4}, \mathrm{Co}_{0.65} \mathrm{Zn}_{0.35} \mathrm{Fe}_{2} \mathrm{O}_{4}\right)$ were also utilized in multiferroic composites [3,8-15].

Among the spinel ferrites, large magnetostrictive cobalt ferrite $\mathrm{CoFe}_{2} \mathrm{O}_{4}(\mathrm{CFO})$ is widely studied due to its high Curie temperature (TC $\sim 793 \mathrm{~K}$ ), large magneto-crystalline anisotropy, high 
coercivity, moderate saturation magnetization, chemical stability and mechanical hardness [1]. Rare-earth ions substitution into $\mathrm{Fe}^{3+}$-site in $\mathrm{AB}_{2} \mathrm{O}_{4}$ type spinel ferrites has been reported to induce structural distortion and strain and thus significantly modifies the electrical and magnetic properties [16-21]. Rare-earth (Ho, Er, Tm, Yb, Lu) ion doping/substitution into cobalt ferrite tend to decrease the room-temperature magnetization as well as the Curie point [22]. Magnetic properties of nanocrystalline Sm-substituted CFO synthesized by citrate precursor method was reported by Rashad et al. [5]. However addition of $\mathrm{Sm}^{3+}$ ions resulted in decreased saturation magnetization and coercivity. Decreased saturation magnetization with an increase in samarium content was also observed for samarium substituted CFO nanopowder synthesized by sol-gel method and this decrease is attributed to the decrease in the net magnetic moment due to the substitution of nonmagnetic ion in the octahedral site [19]. The temperature dependence of magnetization studies of gallium (Ga)-substituted cobalt ferrite $\left(\mathrm{CoGa}_{x} \mathrm{Fe}_{2-x} \mathrm{O}_{4}\right)$ revealed the magnetization increase for lower $\mathrm{Ga}^{3+}$ content $(x=0.2$ and 0.4$)$ when compared to pure $\mathrm{CFO}$ at low temperature and as the temperature increased from $10 \mathrm{~K}$ to $400 \mathrm{~K}$ magnetization decreased $(x=0.4)$ [23]. Negligible room temperature magnetization with more than two-fold increase in coercivity [ $\sim 29 \mathrm{kA} / \mathrm{m}$ for $x=0$ to $\sim 66 \mathrm{kA} / \mathrm{m}$ for $\mathrm{x}=0.02]$ was reported for Er-doped cobalt-ferrite nanocrystals by a sol-gel assisted auto combustion method because of their low magneticordering temperature $(<90 \mathrm{~K})$ [24]. Substitution of $\mathrm{Gd}^{3+}$ and $\mathrm{Nd}^{3+}$ for $\mathrm{Fe}^{3+}$ induces a decrease in the saturation magnetization and Curie temperature of the nickel ferrite [20]. Similarly, substitution of $\mathrm{Dy}^{3+}$ for $\mathrm{Fe}^{3+}$ causes a decrease in the saturation magnetization and Curie temperature of the nickel ferrite [25]. Recent results by our group proved that the larger ionic size $\mathrm{Gd}^{3+}(0.938 \AA)$ ion substitution at $\mathrm{Fe}^{3+}(0.645 \AA)$ in spinel cobalt ferrites will have a profound influence on the structural, electrical conduction and dielectric properties [1,26,27]. 
The obvious aim and relevance of the present work is to understand the Gd-induced chemical changes in cobalt ferrite and magnetic properties of cobalt ferrite. To examine the effect of gadolinium $\left(\mathrm{Gd}^{3+}\right)$ incorporation into $\mathrm{CFO}$ and understand the Gd-induced chemical bonding changes, Raman spectroscopy coupled with X-ray diffraction has been employed. Understanding the chemical structure changes and correlating with magnetic properties of these CFGO materials is expected to further enhance our current understanding of the RE-ion substitution in ferrites. The effect of Gd substitution on the chemical structure magnetic properties is reported in this paper.

\section{Experimental section}

The CFGO polycrystalline compounds were prepared from $99.99 \%$ pure $\mathrm{CoO}, \mathrm{Fe}_{2} \mathrm{O}_{3}$, and $\mathrm{Gd}_{2} \mathrm{O}_{3}$ by the solid state reaction method. Powders of the starting materials were ground in an agate mortar and pestle for $2 \mathrm{~h}$ in an ethanol medium and the mixtures were heat treated in air at $1200{ }^{\circ} \mathrm{C}$ for $12 \mathrm{~h}$ employing controllable furnace with a ramp rate of $10{ }^{\circ} \mathrm{C} / \mathrm{min}$ for both heating and cooling. Calcined powders were mixed with PVA binder and pressed in a Carver press at 4.5 tons, sintered at $1300{ }^{\circ} \mathrm{C}$ for 12 hours. The pellet diameter and thickness were $\sim 7.9 \mathrm{~mm}$ and $1.5 \mathrm{~mm}$, respectively. Phase identification and crystal structure of the materials synthesized were investigated using X-ray diffraction (XRD) measurements employing a Bruker D8 Discover Xray diffractometer. Measurements were made at room temperature using $\mathrm{CuK} \alpha$ radiation $(\lambda=1.5406 \AA$ ). The Raman spectral analysis (Lasos 77, argon laser source: $\lambda=\mathrm{nm}$ and $10 \mathrm{~mW}$ power, and range: $200-900 \mathrm{~cm}^{-1}$ ) was performed on the sintered samples. The magnetic characterization was performed using Quantum-Design MPMS-3 superconducting quantum interference device magnetometer. 


\section{Results and Discussion}

\subsection{X-ray diffraction}

XRD patterns of pristine $\mathrm{CFO}$ and Gd-substituted CFO (CFGO) are shown in Fig. 1(a). XRD patterns revealed that the pristine $\mathrm{CFO}$ and CFGO ceramics were in the inverse spinel phase, along with the peaks corresponding to minor amount of ortho-ferrites $\left(\mathrm{GdFeO}_{3}\right)$ is also observed for $x \geq 0.2$ in CFO. As shown in the Fig.1, all the diffraction peaks were indexed to a simple cubic structure with $\mathbf{F} \mathbf{d} \overline{3} \mathbf{m}$ space symmetric group, according to the standard CFO powder diffraction data (JCPDS 22-1086). Formation of these Ortho-ferrites $\left(\mathrm{REFeO}_{3}\right)$ is common for rare-earth ion doped ferrites [1,26-34]. Lattice parameters for the CFO and CFGO ceramics were

in the range of 8.373-8.394 $\AA$. As the Gd content increases, there is an increase in both lattice parameter and volume of the unit cell, this volume expansion is due to complete incorporation of the rare-earth Gd ions into the unit cell leading to expansion. Complete incorporation of large ionic radius $\mathrm{Gd}^{3+}(0.938 \AA)$ into smaller $\mathrm{Fe}^{3+}(0.645 \AA)$ in CFO lattice leads to increase in lattice parameter. When compared to lattice parameters of Dy substituted $\mathrm{NiFe}_{2} \mathrm{O}_{4}$ [31], Hf substituted CFO powders, Gd substituted CFO powders have shown higher magnitude of lattice expansion [32]. Similar behavior was also observed in $\mathrm{Sm}$ and $\mathrm{Ho}$ substituted $\mathrm{NiFe}_{2} \mathrm{O}_{4}$ [33].

\subsection{Raman spectroscopy}

Raman spectroscopy measurements in the wave number region $150-900 \mathrm{~cm}^{-1}$ at room temperature are carried out to further reveal to structural characteristics of the cobalt ferrite with the doping of the $\mathrm{Gd}^{3+}$ ions. Inverse spinel structured cobalt ferrite with cubic $O^{7}{ }_{h}(\mathbf{F d} \mathbf{3} \mathbf{m})$ symmetry space group has 39 normal vibrational modes, out of which the five active Raman 
modes are $3 \mathrm{~T}_{2 \mathrm{~g}}+\mathrm{E}_{\mathrm{g}}+\mathrm{A}_{1 \mathrm{~g}}[35,36]$. However there are additional 12 Raman modes which are inactive include: $\mathrm{T}_{1 \mathrm{~g}}, 2 \mathrm{~A}_{2 \mathrm{u}}, 2 \mathrm{E}_{\mathrm{u}}, 4 \mathrm{~T}_{1 \mathrm{u}}(\mathrm{IR}), \mathrm{T}_{1 \mathrm{~g}}$ (acoustic), and $2 \mathrm{~T}_{2 \mathrm{u}}$ are largely inactive in spinel structure. These additional Raman modes may be expected in inverse spinel structured ferrites due to random distribution of cations among A and B sites, defects induced lattice distortions, and short range ordering of cations on $\mathrm{B}$ sites $[37,38]$. In spinel structure the metallic cations occupy either surrounded by six oxygen ions to form an octahedron, or by four oxygen ions to form a tetrahedron.

Fig.2 shows the room temperature Raman spectra for pristine and Gd substituted CFO $(\mathrm{x}=0.0-0.3)$. Furthermore, the spectra in Fig. 2, did not exhibit any other Raman modes that corresponds to impurity phases confirming the chemical quality of CFGO compounds. As shown in the Fig.2, all the Raman modes are consistent with those reported for other cubic inverse spinel ferrite structures, which belong to the $O^{7}{ }_{h}(\mathbf{F d} \overline{3} \mathbf{m})$ space group. The vibrational modes observed were in close agreement with those reported for polycrystalline $\mathrm{CoFe}_{2} \mathrm{O}_{4}[36,39]$. CFO and CFGO ceramics have shown six peaks. Table 1 presents the wavenumber corresponding to Raman active peaks, most of which are the typical modes of the cubic inverse-spinel ferrite structure. The two Raman modes at around $\mathrm{T}_{1 \mathrm{~g}}(2) \sim 468-471 \mathrm{~cm}^{-1}$ and $\mathrm{A}_{1 \mathrm{~g}}(1) \sim 687-693 \mathrm{~cm}^{-1}$ are the characteristic modes of spinel ferrite: the low-frequency mode at $\mathrm{T}_{1 \mathrm{~g}}(2)$ is assigned as the vibrations of the octahedral sublattice, whereas the high energy phonon mode at $\mathrm{A}_{1 \mathrm{~g}}(1)$ originates from vibrations of the tetrahedral sublattice.

To get more detail and accurate information from Raman spectra, both low and high frequency Raman spectra were fitted by superposition of Lorentz peaks expressed by using equation number (1): 


$$
\mathrm{I}(\omega)=\mathrm{I}_{0}+\frac{2 \mathrm{~A}}{\pi} \frac{\mathrm{W}}{\mathrm{W}^{2}+4\left(\omega-\omega_{0}\right)^{2}}
$$

where $\omega_{0}$ is phonon frequency of the peak, W is its FWHM, A is a constant, and $\mathrm{I}_{0}$ is intensity of the background. From fitting as shown in Fig.3, the Raman peak positions of the three modes are listed in Table 2 with a very little shift to higher wavenumber region to that of unfitted data (Table1). The deconvoluted Raman spectra for all the major peaks at for pristine CFO and Gd substituted CFO ( $x=0.0-0.3)$ are shown in the Fig. 3.

In general, CFO Raman vibrational modes below $600 \mathrm{~cm}^{-1}$ and above $600 \mathrm{~cm}^{-1}$ were attributed to vibrations of oxygen within the octahedral site, while vibrations within tetrahedral sites respectively [40]. The Raman spectra for the CFO and CFGO ceramics exhibit an intense and major peaks near 689-694 $\mathrm{cm}^{-1}$ associated with $\mathrm{CFO}\left(\mathrm{A}_{1 \mathrm{~g}}\right.$ mode) is due to symmetric stretching of $\mathrm{Fe}(\mathrm{Co})-\mathrm{O}$ bonds, $\mathrm{T}_{\mathrm{g}}(2)$ around $470-472 \mathrm{~cm}^{-1}, \mathrm{E}_{\mathrm{g}}$ at about $300-307 \mathrm{~cm}^{-1}$ is due to symmetric bending of $\mathrm{Fe}(\mathrm{Co})-\mathrm{O}$ bonds and a relatively weak shoulder peak together with most intense near $205-210 \mathrm{~cm}^{-1}$ which is attributed to the $\mathrm{T}_{1 \mathrm{~g}}$ mode, which is due to translational motion of the whole tetrahedron. Most intense $\mathrm{T}_{\mathrm{lg}}(2)$ Raman mode at around $470 \mathrm{~cm}^{-1}$ is due to asymmetric stretching of $\mathrm{Fe}(\mathrm{Co})-\mathrm{O}$ bonds. $\mathrm{T}_{1 \mathrm{~g}}(2)$ is related to the octahedral site mode that reflects the local lattice effect in the octahedral sub-lattice and the other intense $A_{1 \mathrm{~g}}$ mode at about $700 \mathrm{~cm}^{-1}$ and a small peak at $620 \mathrm{~cm}^{-1}$ are the symmetry vibrations of the metal in the tetrahedral site of $\mathrm{CoFe}_{2} \mathrm{O}_{4}$ [36]. As the Gd content increases in CFO, weakening of $\mathrm{T}_{1 \mathrm{~g}}(1)$ Raman mode is noted which indicates dilution of the long range order of cations in B sites [37]. Raman mode shift towards lower wavenumber region may be attributed to complete incorporation of Gd into the lattice and as well due to the largest atomic mass of Gd when compared to the Fe. As 
state in case of $\mathrm{X}$-ray diffraction patterns, the increase in lattice parameters with volume expansion might be due to complete incorporation of larger ionic radii and $\mathrm{Gd}^{3+}(0.938 \AA)$ into smaller $\mathrm{Fe}^{3+}(0.645 \AA)$ in CFO lattice. And the Raman mode shift towards lower wave number region is in complete agreement with increase in lattice parameter and volume expansion of unit cell in case of XRD measurements.

\subsection{Magnetization measurements (M-H)}

Magnetic field dependence of magnetization measurements were carried out on a vibrating sample magnetometer at room temperature with a maximum applied field of $8 \mathrm{kOe}$. Fig.4 (a-d) shows the magnetization $(M-H)$ curves for Gd substituted cobalt-ferrites. Clearly, the $\mathrm{M}-\mathrm{H}$ hysteresis loops vary with Gd content in CFO. The saturation magnetization (Ms), remnant magnetization $(\mathrm{Mr})$, the coercivity $\left(\mathrm{H}_{\mathrm{C}}\right)$, and remnant squareness ratio $R$ and the magnetic moment $(\mu)$ values are listed in Table 3. The saturation magnetization $(\mathrm{Ms})$ for $\mathrm{CoFe}_{2} \mathrm{O}_{4}$ is $\sim 39$ emu/gm. With increasing $\mathrm{Gd}^{3+}$ substitution, Ms increases from $39 \mathrm{emu} / \mathrm{gm}(x=0)$ to $132 \mathrm{emu} / \mathrm{gm}$ $(x=0.1)$ followed by a drastic decrease to $47 \mathrm{emu} / \mathrm{gm}(x=0.3)$. The $\mathrm{Gd}^{3+}$ substituted cobalt-ferrites $(x \leq 0.2)$ have shown an anomalous improvement in $\mathrm{M}$ values compared to $\mathrm{CoFe}_{2} \mathrm{O}_{4}$. This enhancement in the magnetic properties is attributed to the higher magnetic moment of $\mathrm{Gd}^{3+}\left(4 \mathrm{f}^{7}\right.$ orbital) which is residing in octahedral sites is higher when compared to that of $\mathrm{Fe}^{3+}\left(3 \mathrm{~d}^{5}\right)[36,44]$. This can also be ascribed due to the migration of $\mathrm{Co}^{2+}\left(3 \mathrm{~d}^{7}\right)$ ions from the octahedral to the tetrahedral sites with a magnetic moment aligned anti-parallel to those of rare earth $\left(\mathrm{RE}^{3+}\right)$ ions in the spinel lattice and this increase magnetic properties is also theoretically expected $[36,44]$. Decrease in magnetization once $\mathbf{G d}^{3+}$ content is beyond $\boldsymbol{x}=\mathbf{0 . 1}$ in CFGO might be attributed to compositional saturation in the CFO lattice. Substitution 
of larger ionic radii $(0.938 \AA) \mathrm{Gd}^{3+}$ into smaller $\mathrm{Fe}^{3+}(0.645 \AA)$ in CFO lattice leads to increase in lattice parameter, the contribution of the larger ionic radius in the enhancement of these values is very significant. The $\mathrm{M}-\mathrm{H}$ loops although non-saturating with increasing content of $\mathrm{Gd}$, indicating weak ferromagnetism in the system. The non-saturation of hysteresis loops might be due to magnetic disorder i.e. spins are canted instead of parallel and anti-parallel.

The $\mathrm{GdFeO}_{3}$ phase is a canted antiferromagnetic with a Néel temperature of $674 \mathrm{~K}$ with feeble magnetization. Therefore, there is no considerable contribution from the $\mathrm{GdFeO}_{3}$ phase to the magnetic properties [41]. The magnetic properties of doped/ substituted ferrites mainly arise due to strong superexchange interactions between A- and B-sites cations in the inverse spinel ferrites [42]. However, at higher $\mathrm{Gd}$ content $(x=0.3)$ formation of antiferromagnetic $\mathrm{GdFeO}_{3}$ phase leads to decrease in M. Zoomed portion of M-H loops with coercivity (Hc) for CFO and CFGO ceramics is shown in Fig. 4(e \& $\mathrm{f})$. It is clearly seen from the M-H loops that these materials are ferromagnetic in nature with some remnant magnetization and coercivity values as listed in Table.3. Hc increases with increase of Gd content, the greater the magnetic anisotropy in the material, the greater coercive field. Hence enhancement in Hc is attributed to magnetic anisotropy [45]. Formation of Ortho-ferrite $\left(\mathrm{REFeO}_{3}\right)$ phase is a common feature for rare-earth doped/substituted ferrites, which in turn decreases the magnetization [1,26,27]. Fig.4 gives the dependence of the coercive force on the substitution content for Co-Gd ferrites. It was observed that the coercivity of $\mathrm{CoFe}_{1.9} \mathrm{Gd}_{0.1} \mathrm{O}_{4}$ was larger than that of a pure $\mathrm{CFO}$ ceramics. Calculated squareness ratio $(\mathrm{R}=\mathrm{Mr} / \mathrm{Ms})$ for all measured compositions is also followed the magnetization trend and these values were $\sim 0.106,0.314,0.175$ for $x$ values of 0.0, 0.1 and 0.3, respectively. According to the Stoner-Wohlfarth model, in the case of an ensemble of uniformly magnetized and isotropically distributed particles 
without intergrain interactions the squareness ratio $(R=M r / M s)$ should be 0.5 and if the exchange coupling between adjacent grains take place, then the $R$ value will exceed 0.5 , however it is not in the present CFO and CFGO ceramics [45].

The saturation magnetization Ms value $(132 \mathrm{emu} / \mathrm{gm})$ of the Gd substituted CFO sample at room temperature is greater than that of Dy-doped Ni ferrite $47 \mathrm{emu} / \mathrm{g}$ [25]. From the hysteresis loops, the coercive force $(\mathrm{Hc})$, saturation magnetization $\left(\sigma_{\mathrm{s}}\right)$ and magnetic moments $(\boldsymbol{\mu})$ were obtained (Table 3). The magnetic-moment values were calculated from the $\sigma_{\mathrm{s}}$ values at room temperature using the relation (equation number 2) [43]:

$$
\frac{\mu}{\mu_{\mathrm{B}}}=\frac{\sigma_{\mathrm{s}} \times \text { Molecular Weight }}{5585}
$$

Magnetic moment followed similar trend to that of magnetization, with increasing Gd substitution, $\mu / \mu_{\mathrm{B}}$ increases from $0.806(x=0)$ to $3.086 \mathrm{emu} / \mathrm{gm}(x=0.1)$ followed by a marginal decrease $1.386(x=0.3)$. Similar results were observed for Ga substituted CFO with spin glass behavior [42].

\section{Conclusions}

Chemical bonding, crystal structure and magnetic properties of $\mathrm{CoFe}_{2-x} \mathrm{Gd}_{x} \mathrm{O}_{4}$ polycrystalline ceramics were investigated. The CFGO ceramics exhibit the inverse spinel structure with slightly enlarged cell lattice constants at the substitution content $x \leq 0.2$. The Gd 
substituted ions studied in the present work are considered to be ferromagnetic at room temperature, an initial increase in magnetization was observed for $\mathrm{x} \leq 0.2$ and then monotonous decrease in magnetization for $0.3 \geq x \leq 0.4$ of CFGO was therefore observed for Gd content in CFO.

Acknowledgements: Authors at the University of Texas at El Paso acknowledge, with pleasure, the support from the National Science Foundation (NSF) for the grant \# DMR-1205302. 
References

[1] Md. T. Rahman, M. Vargas, and C. V. Ramana, J. Alloys Compd. 617 (2014) 547.

[2] A. Paul Blessington Selvadurai, V. Pazhanivelu , R. Murugaraj, Appl. Phys. A 119 (2015) 229.

[3] Dhiren K. Pradhan, Pankaj Misra, Venkata S. Puli, Satyaprakash Sahoo, Dillip K. Pradhan, and Ram S. Katiyar, J.Appl.Phys. 115 (2014) 243904.

[4] L. Ben Tahar, M. Artus , S. Ammar, L.S. Smiri , F. Herbst, M.-J. Vaulay, V. Richard ,J.M. Grene`che, F. Villain , F. Fie`’ vet, J. Magn. Magn. Mater. 320 (2008) 3242.

[5] M. M. Rashad, R. M. Mohamed, and H. El-Shall, J. Mat. Proc. Tech. 198 (1-3) (2008) 139.

[6] J. C. Slonczewski, Phys. Rev. B 82 (2010) 054403.

[7] G. E. W. Bauer, E. Saitoh, and B. J. van Wees, Nature Mater. 11 (2012) 391.

[8] Babusona Sarkar, Biswajit Dalal, Vishal Dev Ashok, Kaushik Chakrabarti, Amitava Mitra and S.K.De, J. Appl. Phys. 115 (2014) 123908 .

[9] A.Srinivas, R.V.Krishnaiah, T.Karthik,P.Suresh, Saket Asthana and S.V.Kamat, Appl. Phys. Lett. 101 (2012) 082902.

[10] R. Muralidharan, N. Dix,V. Skumryev, M. Varela, F. Sánchez, and J. Fontcuberta, J. Appl. Phys. 103 (2008) 07E301.

[11] S.Narendra Babu and Leszek Malkinski, J. Appl. Phys. 111 (2012) 07D919.

[12] Dhiren K.Pradhan,Venkata.S.Puli,Satya N.Tripathy, Dillip K.Pradhan,J.F.Scott and Ram S.Katiyar, J. Appl. Phys. 114 (2013) 234106 . 
[13] Dhiren K.Pradhan, Satyaprakash Sahoo, Sujit K.Barik, Venkata S.Puli, Pankaj Misra and Ram S.Katiyar, J. Appl. Phys. 115194105 (2014).

[14] J.L. Gunjakar, A.M. More, V.R. Shinde and C.D. Lokhandea, J. Alloys Compd. 465 (2008) 468.

[15] S. H. Song, C. C. H. Lo, S. J. Lee, S. T. Aldini, J. E. Snyder and D. C. Jiles, J. Appl. Phys. 101 (2007) 09C517.

[16] Zhijun Gu, Xu Xiang, Guoli Fan, and Feng Li, J. Phys. Chem. C 112 (2008) 18459.

[17] Fuxiang Cheng, Chunsheng Liao, Junfeng Kuang, Zhigang Xu, Chunhua Yan, Liangyao Chen, Haibin Zhao and Zhu Liu, J. Appl. Phys. 85 (1999) 2782.

[18] S. J. Lee, C. C. H. Lo, P. N. Matlage, S. H. Song, Y. Melikhov, J. E. Snyder and D. C.Jiles,J. Appl. Phys. 102 (2007) 073910.

[19] Sheena Xavier, Smitha Thankachan, Binu P. Jacob, and E.M.Mohammed, J. Nanosci. 2013 (2013) 1 (Article ID 524380).

[20] K. K. Bharathi, J. A. Chelvane, and G. Markandeyulu, J.Magn. Magn. Mater. 321(22) (2009) 3677.

[21] E. E. Sileo and S. E. Jacobo, Physica B. 354(1-4) (2004) 241.

[22] Fu-Xiang Cheng, Jiang-Tao Jia, Zhi-Gang Xu, Biao Zhou, Chun-Sheng Liao, and Chun-Hua Yan, J.Appl.Phys. 86(5) (1999) 2727 .

[23] N. Ranvah, Y. Melikhov, D. C. Jiles, J. E. Snyder, A. J. Moses, P. I. Williams,1 and S. H. Song, J. Appl.Phys. 103 (2008) 07E506.

[24] Sateesh Prathapani,M. Vinitha, T. V. Jayaraman, and D. Das, J.Appl.Phys. 115 (2014) 17A502. 
[25] K. Kamala Bharathi, K. Balamurugan, P. N. Santhosh, M. Pattabiraman, and G. Markandeyulu, Phys. Rev. B 77 (2008) 172401(1-4).

[26] Md. T. Rahman and C. V. Ramana, J.Appl..Phys.116 (2014) 164108.

[27] Md.T. Rahman, C.V. Ramana, Ceramics International 40 (2014) 14533.

[28] K. Kamala Bharathi, G. Markandeyulu, and C. V. Ramana, J. Phys. Chem.C 115 (2010) 554.

[29] K. Kamala Bharathi and C. V. Ramana, J. Mater. Res. 26 (2011) 584.

[30] K. Kamala Bharathi, G. Markandeyulu, and C. V. Ramana,J. Electrochem. Soc. 158 (2011) 71.

[31] K. Kamala Bharathi,a M. Noor-A-Alam,a R.S. Vemuriab and C. V. Ramana, RSC Advances 2 (2012) 941.

[32] S. Wells, C.V. Ramana, Ceramics International 39 (2013) 9549.

[33] K. Kamala Bharathi, G. Markandeyulu and C. V. Ramana, Electrochem. Solid-State Lett. 13 (2010) G98.

[34] Jianhong Peng, Mirabbos Hojamberdiev, Yunhua Xu, Baowei Cao, Juan Wang and Hongn Wu, J. Magn. Magn. Mater. 323 (2011) 133.

[35] M.A.G. Solera, T.F.O. Melo, S.W. da Silva, E.C.D. Lima, A.C.M. Pimenta, V.K. Garg, A.C. Oliveira, P.C. Morais, J. Magn. Magn. Mater. 272-276 (2004) 2357.

[36] S.R. Naik , A.V. Salker , S.M. Yusuf, S.S. Meena, Journal of Alloys and Compounds 566 (2013) 54. 
[37] K.S. Aneesh Kumar, R.N. Bhowmik, Mater. Chem. Phys. 146 (2014) 159.

[38] V. G. Ivanov, M. V. Abrashev, M. N. Iliev, M. M. Gospodinov, J. Meen, and M. I. Aroyo, Phys. Rev. B 82, (2010) 024104.

[39] M.A.G. Solera, T.F.O. Melo, S.W. da Silva, E.C.D. Lima, A.C.M. Pimenta, V.K. Garg, A.C. Oliveira, P.C. Morais, J. Magn. Magn. Mater. 272-276 (2004) 2357.

[40] S. Urcia-Romero, O. Perales-Pérez, and G. Gutiérrez, J.Appl.Phys. 107 (2010) 09A508.

[41] Jyoti Shah and Ravinder Kumar Kotnala, Scripta Materialia 67 (2012) 316.

[42] Mohamed Bakr Mohamed, M. Yehia, J. Alloys Comp. 615 (2014) 181.

[43] Utpal Bhattacharya and Vishu S. Darshane, J. Mater. Chem. 3(3) (1993) 299.

[44] S. R. Naik and A. V. Salker J. Mater. Chem. 22 (2012)2740.

[45] Fenlian Zan, Yongqing Ma, Qian Ma, Yuanfeng Xu, Zhenxiang Dai, Ganhong Zheng, Mingzai Wu and Guang Li, J. Am. Ceram. Soc., 96 [10] (2013) 3100. 


\section{Figure Captions}

Figure 1 XRD patterns of $\mathrm{CoFe}_{2-x} \mathrm{Gd}_{x} \mathrm{O}_{4}(\mathrm{CFGO})$ compounds as a function of $x$. The data indicate that pure and Gd-substituted CFO compounds crystallize in inverse spinel structure. As indicated, secondary phase $\mathrm{GdFeO}_{3}$ peaks appear with increasing $\mathrm{Gd}$ content.

Figure 2 Room temperature Raman spectra of $\mathrm{CoFe}_{2-x} \mathrm{Gd}_{x} \mathrm{O}_{4} \quad(\mathrm{CFGO}, \quad x=0.0-0.3)$ compounds as a function of wave number $\left(\mathrm{cm}^{-1}\right)$

Figure 2 Experimental and fitted Raman spectra of $\mathrm{CoFe}_{2-x} \mathrm{Gd}_{x} \mathrm{O}_{4}$ (CFGO, $\left.x=0.0-0.3\right)$ compounds as a function of wave number $\left(\mathrm{cm}^{-1}\right)$, (Solid lines are experimental data, blue line are individual peaks and red lines are whole spectrum peaks after fitting).

Figure 4 Room temperature magnetization-filed (M-H) hysteresis loops of $\mathrm{CoFe}_{2-x} \mathrm{Gd}_{x} \mathrm{O}_{4}$ (CFGO, $x=0.0-0.3$ ) (inset show the zoomed portions of coercivity for different samples) 


\section{Table Captions}

Table 1. Room temperature Raman peaks of $\mathrm{CoFe}_{2-x} \mathrm{Gd}_{x} \mathrm{O}_{4}(\mathrm{CFGO}, x=0.0-0.3)$ compounds.

Table 2. Room temperature Raman fitting peak position of $\mathrm{CoFe}_{2-x} \mathrm{Gd}_{x} \mathrm{O}_{4}(\mathrm{CFGO}, x=0.0-0.3)$ compounds.

Table 3. Effect of $\mathrm{Gd}$ substitution on magnetic parameters [Saturation Magnetization- Ms,

Remanent Magnetization- Mr, Coercive field, Squareness ratio - $\mathrm{R}=\mathrm{Mr} / \mathrm{M} s$, Magnetic moment $\left.\left(\mu / \mu_{\mathrm{B}}\right)\right]$ of $\mathrm{CoFe}_{2-x} \mathrm{Gd}_{x} \mathrm{O}_{4}$ compounds. 
Fig.1

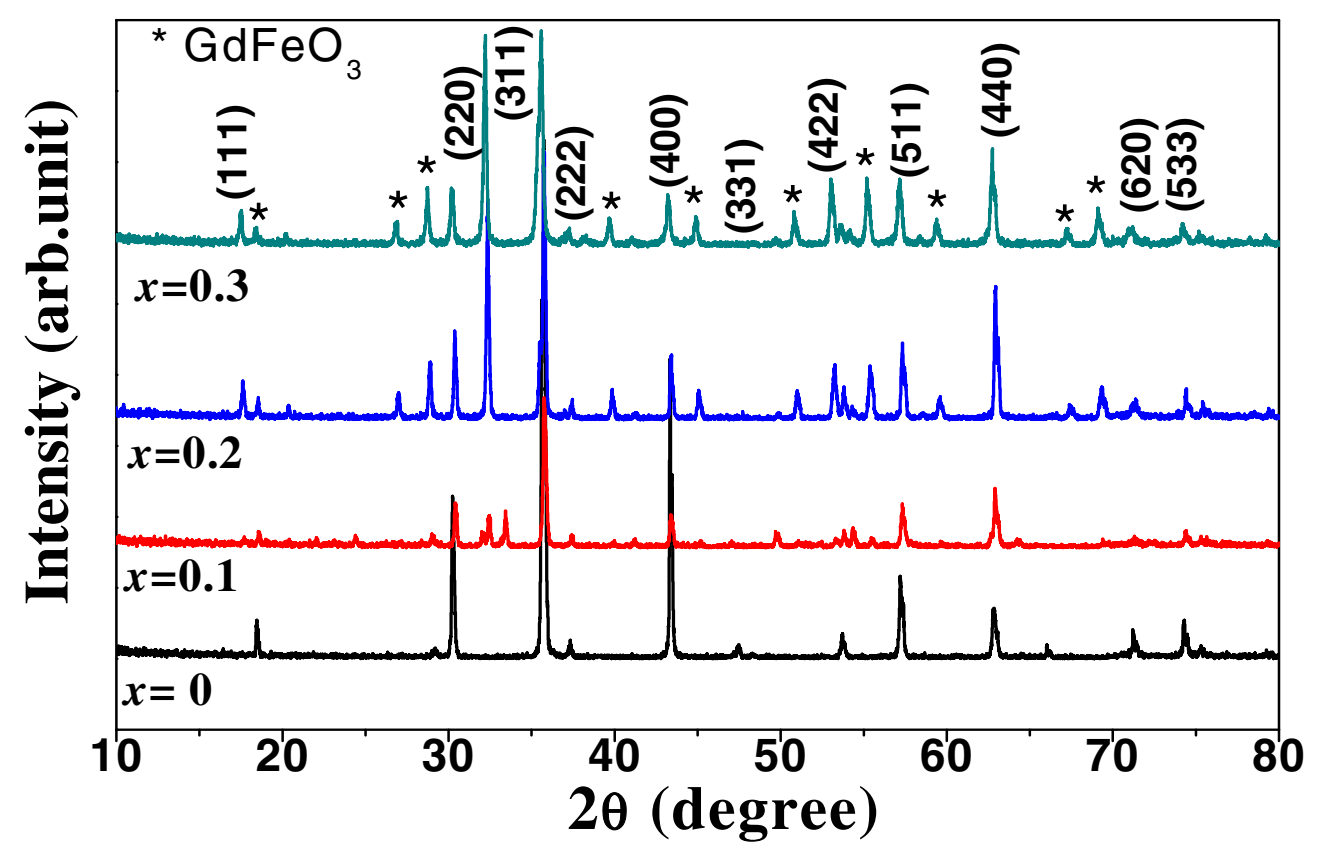


Fig.2

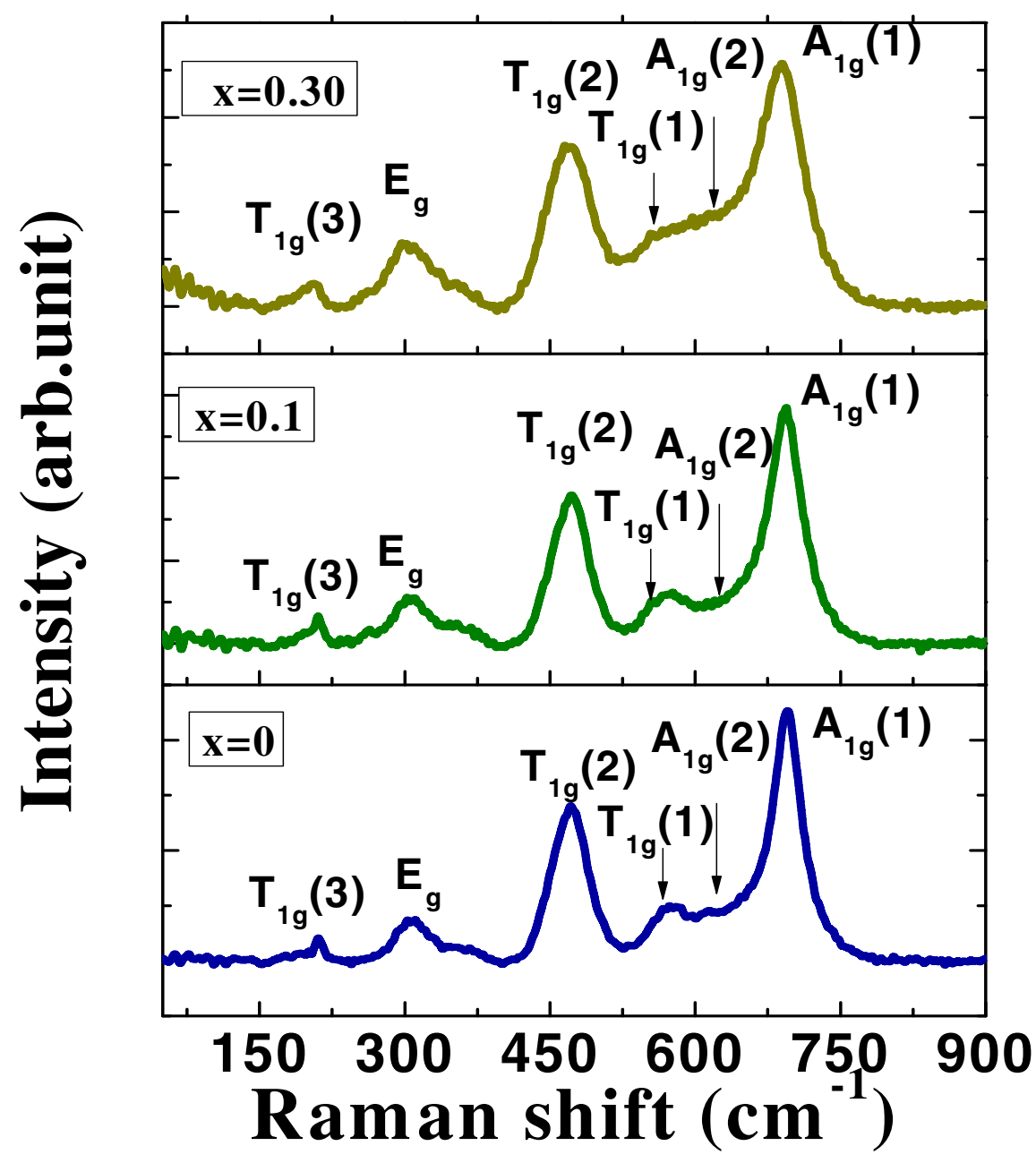


Fig.3
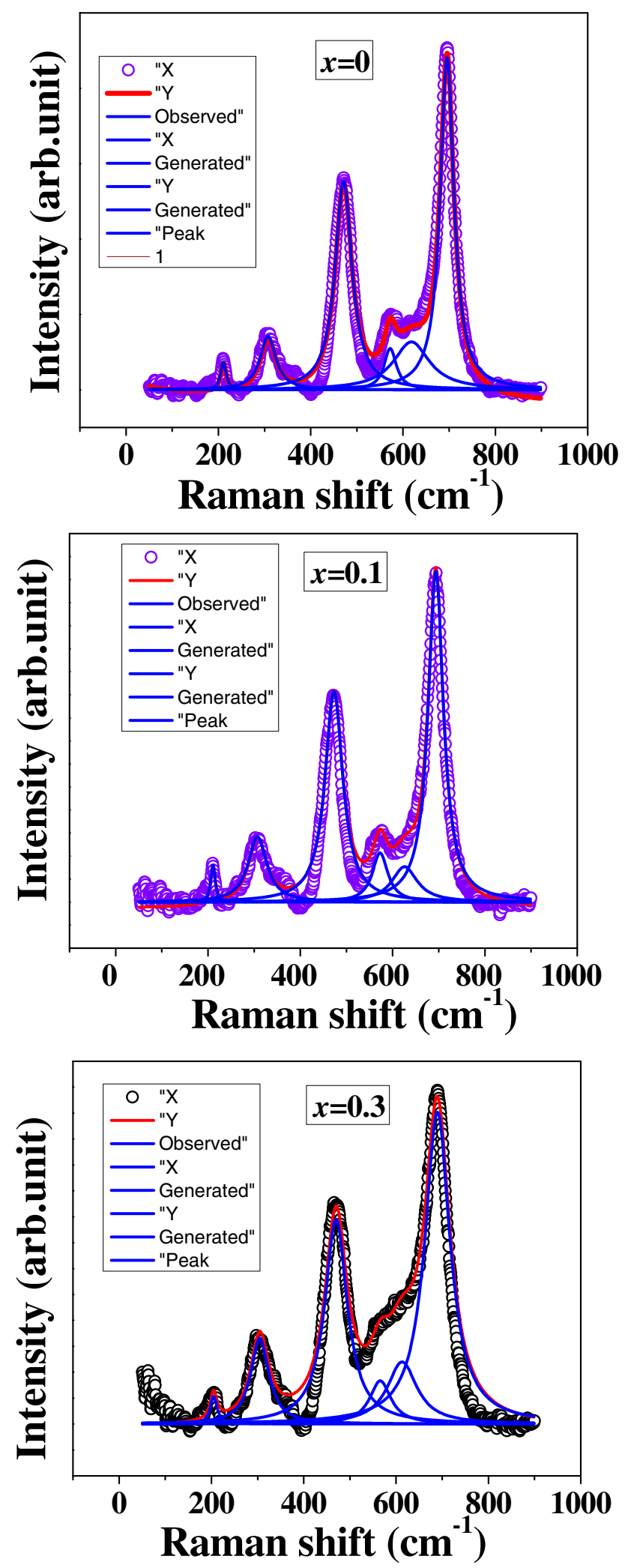
Fig.4
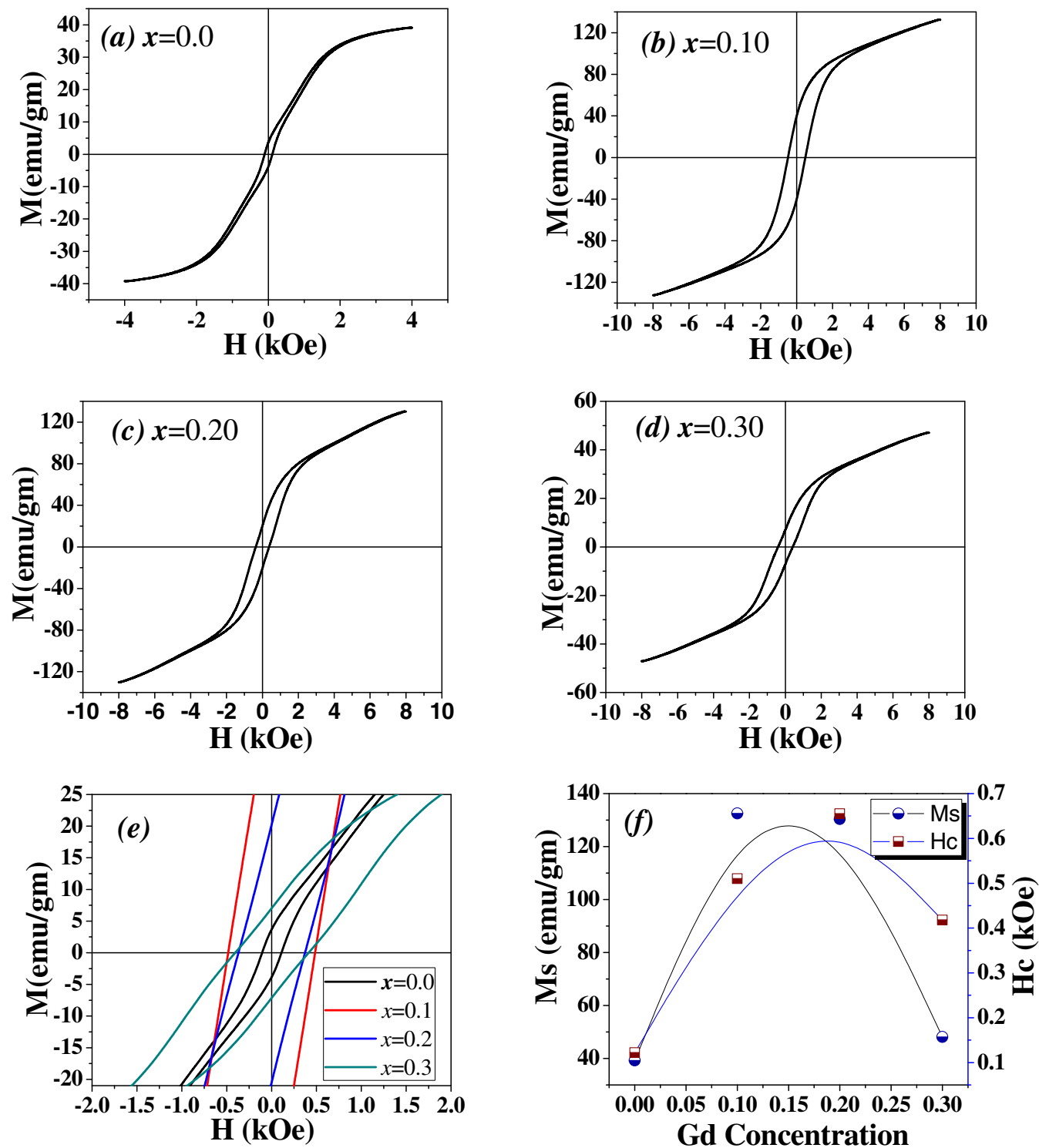
Graphical Abstract

Room temperature Raman spectra of $\mathrm{CoFe}_{2-x} \mathrm{Gd}_{x} \mathrm{O}_{4}$ (CFGO, $\left.x=0.0-0.3\right)$ compounds as a function of wave number $\left(\mathrm{cm}^{-1}\right)$

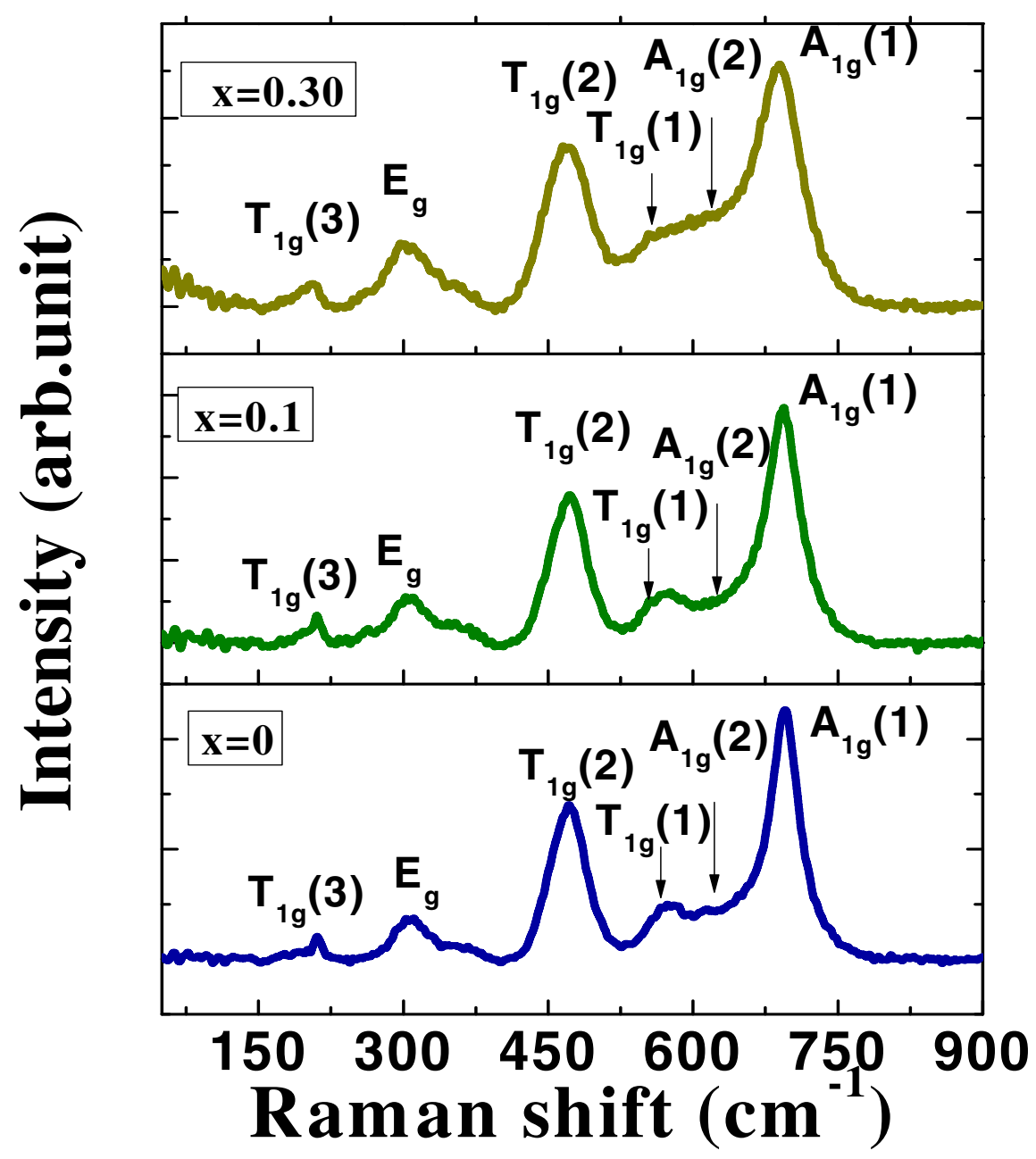


Table 1. Room temperature Raman peaks of $\mathrm{CoFe}_{2-x} \mathrm{Gd}_{x} \mathrm{O}_{4}$ (CFGO, $x=0,0.1,0.3$ ) compounds.

\begin{tabular}{|c|c|c|c|c|c|c|}
\hline $\mathrm{CoFe}_{2-x} \mathrm{Gd}_{x} \mathrm{O}_{4}$ & $\begin{array}{c}T_{1 g}(3) \\
\text { Translatio } \\
\text { nal motion }\end{array}$ & $\begin{array}{c}E_{g} \\
\text { Symmetric } \\
\text { bending }\end{array}$ & $\begin{array}{c}T_{1 g}(2) \\
\text { Asymmetric } \\
\text { stretching }\end{array}$ & $\begin{array}{c}T_{1 g}(1) \\
\text { Asymmetric } \\
\text { bending }\end{array}$ & $\begin{array}{c}A_{1 g}(1) \\
\text { Symmetric } \\
\text { stretching }\end{array}$ & $\begin{array}{c}A_{1 g}(2) \\
\text { Symmetric } \\
\text { stretching }\end{array}$ \\
\hline$x=0$ & 210 & 307 & 471 & 575 & 615 & 694 \\
\hline$x=0.1$ & 210 & 306 & 472 & 573 & 611 & 693 \\
\hline$x=0.3$ & 205 & 300 & 470 & 572 & 603 & 689 \\
\hline
\end{tabular}


Table 2. Deconvoluted room temperature Raman peaks of $\mathrm{CoFe}_{2-x} \mathrm{Gd}_{x} \mathrm{O}_{4}(\mathrm{CFGO}$, $x=0,0.1,0.3)$ compounds.

\begin{tabular}{|c|c|c|c|c|c|c|}
\hline $\mathrm{CoFe}_{2-x} \mathrm{Gd}_{x} \mathrm{O}_{4}$ & $T_{1 g}(3)$ & $E_{g}$ & $T_{1 g}(2)$ & $T_{1 g}(1)$ & $A_{1 g}(1)$ & $A_{1 g}(2)$ \\
& $\begin{array}{c}\text { Translatio } \\
\text { nal motion }\end{array}$ & $\begin{array}{c}\text { Symmetric } \\
\text { bending }\end{array}$ & $\begin{array}{c}\text { Asymmetric } \\
\text { stretching }\end{array}$ & $\begin{array}{c}\text { Asymmetric } \\
\text { bending }\end{array}$ & $\begin{array}{c}\text { Symmetric } \\
\text { stretching }\end{array}$ & $\begin{array}{c}\text { Symmetric } \\
\text { stretching }\end{array}$ \\
\hline$x=0$ & 210.984 & 307.575 & 471.212 & 572.222 & 618.181 & 695.454 \\
\hline$x=0.1$ & 210.985 & 307.333 & 472.933 & 572.819 & 625.821 & 693.601 \\
\hline$x=0.3$ & 204.869 & 304.716 & 469.875 & 565.684 & 613.080 & 689.524 \\
\hline
\end{tabular}


Table 3. Effect of $\mathrm{Gd}$ substitution on magnetic parameters [Saturation Magnetization- $M s$, Remnant Magnetization- $M r$, Cercieve field, Squareness ratio - $R=M r / M s$, Magnetic moment $\left(\mu / \mu_{\mathrm{B}}\right)$ of $\mathrm{CoFe}_{2-x} \mathrm{Gd}_{x} \mathrm{O}_{4}$.

\begin{tabular}{|l|l|l|l|l|l|}
\hline $\begin{array}{l}\mathrm{CoFe}_{2-x} \mathrm{Gd}_{x} \mathrm{O}_{4} \\
(\mathrm{Gd} \text { content })\end{array}$ & $\begin{array}{l}M s \\
(\mathrm{emu} / \mathrm{g})\end{array}$ & $\begin{array}{r}M r \\
(\mathrm{emu} / \mathrm{g})\end{array}$ & $\begin{array}{c}H c \\
(\mathrm{kOe})\end{array}$ & $\begin{array}{l}R=M r / M s \\
(\text { squareness } \\
\text { ratio })\end{array}$ & $\begin{array}{l}\text { Magnetic } \\
\text { moment } \\
\left(\mu / \mu_{\mathrm{B}}\right)\end{array}$ \\
\hline$x=0$ & 39.25 & 4.17 & 0.122 & 0.106 & 0.806 \\
\hline$x=0.1$ & 132.5 & 41.7 & 0.510 & 0.314 & 3.086 \\
\hline$x=0.2$ & 130.36 & 17.29 & 0.655 & 0.132 & 3.551 \\
\hline$x=0.3$ & 48.15 & 8.43 & 0.418 & 0.175 & 1.386 \\
\hline
\end{tabular}

